\title{
INFLUENCE OF CYCLIC LOADING ON FATIGUE BEHAVIOUR OF SBR AND NBR COMPOUNDS WITH DIFFERENT CONTENTS OF CARBON BLACK
}

\author{
Abdullah Mohammed ${ }^{1, ~ *}$, Mahmoud M. Nemat-Alla ${ }^{2}$, Karam M. Emara ${ }^{3}$ \\ ${ }^{1,3}$ Mechanical Engineering Department, Assiut University, Assiut, Egypt. \\ ${ }^{2}$ Mechanical Engineering Department, Kafrelsheikh University, Kafrelsheikh, Egypt.
}

Received 16 December 2013; accepted 31 December 2013

\begin{abstract}
Rubber is used in many industrial applications, specially those need high damping capability. In present work, the effects of cyclic loading conditions on fatigue lifetime of the styrene butadiene (SBR) and nitrile-butadiene rubber (NBR) with 0,20,30,50 and $70 \mathrm{Phr}$ of carbon black contents were investigated. Two cyclic loading conditions, namely full relaxation and non-relaxation tension, were considered. It was found that, in full relaxation tension test, i.e. $\mathrm{R}=0$, fatigue lifetime increased with the decrease of the maximum strain. The decrease of maximum strain was accompanied with decrease in the maximum stress and stress amplitude. It was also found that, in non-relaxation tension test i.e. $\mathrm{R}>0$, fatigue lifetime increased with the increase of the minimum strain, as well as, with the decrease of the stress amplitude. In this case, fatigue lifetime increased in spite of the fact that the increase of the minimum strain was accompanied with increase in the maximum stress at constant maximum strain. Consequently, it was found that the increase of minimum strain was beneficial in increasing the lifetime. It was also found that fatigue lifetime of rubber could be improved by increasing the carbon black content at the test conditions used in experiments.
\end{abstract}

Keywords: Rubber, Fatigue lifetime, Carbon black, Full relaxation tension and Non-relaxation tension.

\section{Introduction}

Rubber is used in many industrial applications because of its large elastic deformation and great damping capabilities. Rubber parts, such as tires, seals, engine mounts and vibration isolators are often subjected to cyclic loading conditions in use. When these parts are subjected to fluctuating loads, they often fail due to nucleation and growth of defects or cracks. Many factors influence the fatigue behaviour of rubber. it has been found that [14], the main factors affecting fatigue cracking in rubber are mechanical, thermal, environmental and chemical factors. The mechanical factor comprises the maximum and minimum strains, (or stresses), type of loading (tension or compression), waveform and the loading frequency. In service, rubber is usually subjected to different cyclic loading conditions. Therefore, fatigue analysis and effect of load on fatigue lifetime are very important criterion for design engineer to assure the safety and reliability of mechanical rubber components.

Fatigue lifetime is conventionally defined as the number of cycles to break a specimen into two pieces at a particular stress for stress-controlled tests, or at a particular strain for strain-controlled tests. Usually, for obtaining an average value of rubber fatigue life a large number of samples are necessary, which is a time consuming process. Two general approaches to fatigue analysis are available depending on the goals of the investigation, namely, fatigue crack nucleation and fatigue crack growth. The fatigue crack nucleation approach focuses on the life of a component until a crack is formed. The fatigue crack growth approach focuses on the growth of existing cracks or flaws in the material[3,4].

\footnotetext{
* Corresponding author.
} 
Traditionally, the fatigue characteristics of materials, including rubbers, were determined by a "Wöhler" curve, also known as S-N curve ( $\mathrm{S}$ denotes the applied dynamic stress $\sigma$ for a stress-controlled test or, alternatively, strain $\varepsilon$ for a strain-controlled test, and $\mathrm{N}$ is the number of cycles to failure). Conventional fatigue tests can be categorized into broadly four types, namely, a periodic loading between fixed stress limits, in tension or compression (load control), periodic loading between fixed strain limits in tension or compression (displacement control), reversed shear stresses obtained by torsional deformation and reversed bending stresses in one dimension (flexing of a sheet) or two dimensions (rotary deflection of a cylinder) [5]. Mars and Fatemi [6] have stated that, no standard test yet exists for measuring the fatigue crack growth curve in rubber, however, the procedures and analytical methods are reasonably well documented in the literature, and are in widespread use, at least for the case of $\mathrm{R}=0$ cyclic loading, where $\mathrm{R}$ is the ratio of the minimum to maximum stresses (or strains). Fatigue in materials is caused by repeated loading and unloading cycles to maximum stresses below the ultimate strength of a material. This cyclic loading causes a progressive degradation of the material resistance to loading and eventual leads to failure. In many constant amplitude load controlled fatigue experiments, a specimen is loaded sinusoidal in time with the stress. Common parameters for describing cyclic loading are shown in Fig.1, and different loading regimes characterized by R-ratio are shown graphically in Fig.2[7]. The location of the initiation of damage is strongly related to the stress distribution, shear stress and hydrostatic pressure [8]. The improved fatigue resistance with increased minimum and maximum stresses was explained previously by Gent [9]. He has attributed this improvement to the strain crystallization of natural rubber (NR) which inhibits crack growth. Kim and Jeong [10] have mentioned that, when a rubber component filled with carbon black is subjected to loading, the rubber matrix around carbon black is strained more than the rest. They, also showed that, if a large or repeated force is applied, carbon black is separated from the matrix nucleating microcracks. Also, there are other sources of microcracks in rubber including contaminants or voids in the matrix, imperfectly dispersed compounding ingredients and surface flaws.

Mars and Fatemi [1]have mentioned that, the effect of minimum or mean loading on fatigue life depends greatly on polymer and filler types. Where, in rubbers that exhibit strain-crystallization, increasing the minimum strain has a significant beneficial effect, to a certain threshold. However, in rubbers that do not exhibit strain-crystallization, increasing the minimum strain can have a deleterious effect but not necessarily. In addition, they proved in experimental results in [6], that the important effect of minimum strain on fatigue life of $\mathrm{NR}$, at macro-crack nucleation tests with $\mathrm{R}>0$ cyclic loading resulted in an increase in the fatigue life, as compared with $\mathrm{R}=0$ tests.

Abraham et al. [11]carried out fatigue tests on ethylene propylene (EPDM) and styrenebutadiene rubber(SBR), under uniaxial cyclic tests, using cylindrical dumbbell specimens, having a zero minimum stress $\left(\sigma_{\min }=0\right)$ and varying stress amplitude $\left(\sigma_{\mathrm{a}}\right)$. The experimental results of this work showed that the dynamic fatigue properties of filled EPDM and SBR elastomers at constant temperature and frequency depend on the applied stress amplitude as well as minimum stress. Increasing minimum stresses with constant strain amplitude can increase the service life by a factor greater than 10 despite the concurrent increase in maximum stresses. These effects do not apply to unfilled rubber. Since EPDM and SBR do not exhibit strain crystallization, then strain crystallization cannot be used to explain the increase in service life. It is evident that the phenomenon of 
increased fatigue life with increased maximum stress is related to the properties of the rubber filler system.

Kim and Jeong [10] have investigated experimentally and examined the effects of carbon black on the fatigue life, the hysteresis, the fracture surface morphology and the critical J-value of natural rubber compounds filled with three kinds of carbon black N330, N650 or N990. The fatigue test was conducted at room temperature, $23{ }^{\circ} \mathrm{C}$, and controlled displacement. The displacement was prescribed as a sinusoidal pulse at frequency of $1 \mathrm{~Hz}$ with maximum displacement of 16, 19 or $22 \mathrm{~mm}$ and zero minimum displacement. The results showed in the NR compound filled with N650, that there existed large carbon black agglomerates. Thus, the fatigue life of the NR compound filled with N650 was shorter.

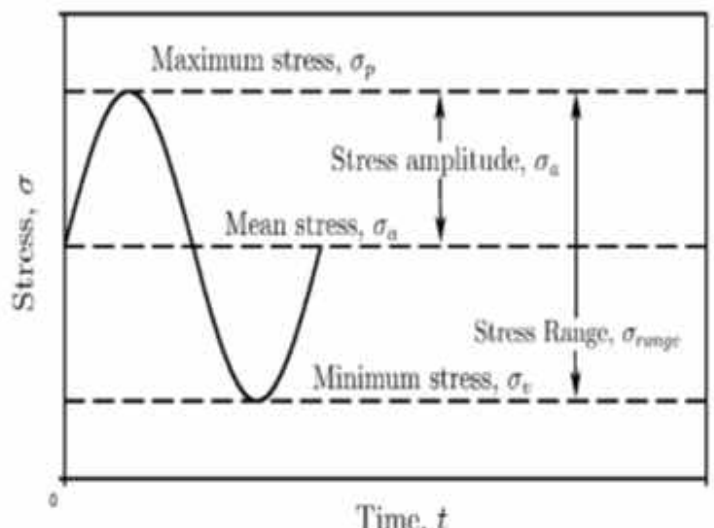

Fig. 1. Illustration of sinusoidal loading and the relevant terminology to describe it[7].

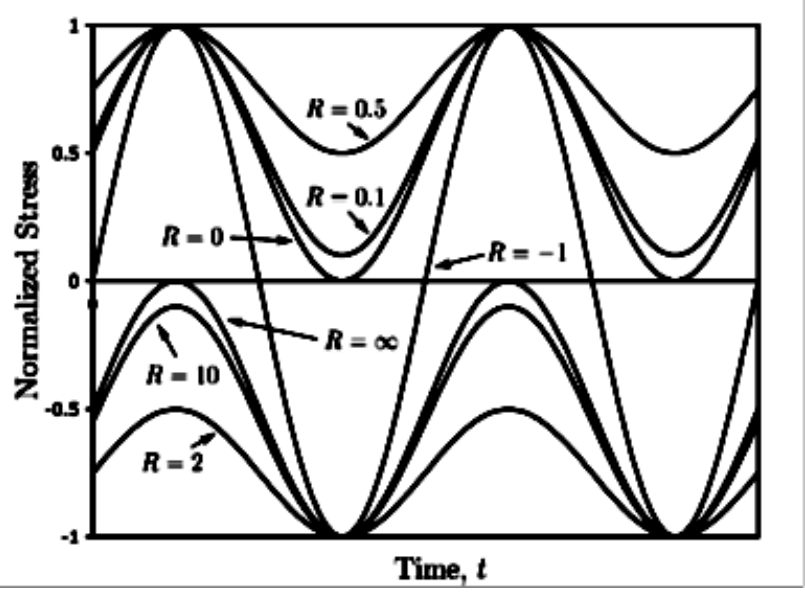

Fig. 2. Illustration of different loading R-ratios normalized to a maximum absolute value stress of 1.0[7].

Cam et al. [12] have described macroscopic fatigue damage in carbon black-filled natural rubber (CB-NR) under uniaxial loading conditions with different values of R ratio, namely, uniaxial tension-compression, fully relaxing uniaxial tension and non-relaxing uniaxial tension loading conditions. They observed that, only one type of fatigue damage took place for uniaxial tension-compression and fully relaxing uniaxial tension loading conditions, and that several different types of fatigue damage took place in non-relaxing uniaxial tension loading conditions. Negative loading ratios, R, the fatigue life decreases as the 
stress amplitude increases, whereas the tendency is reversed soon as $\mathrm{R}$ ratio becomes positive [13]. Harbour et al. [14,15]investigated the effects of variable amplitude loading conditions on the fatigue lives of multiaxial rubber specimens. Two filled rubber materials were used and compared to investigate the effects of strain-crystallization on crack development, namely, NR, which strain crystallizes, and SBR, which does not. Also, they investigated the fatigue crack growth behaviour of NR and SBR, where, NR was shown to be very sensitive to changes in the R-ratio, while the fatigue crack growth rates drastically dropped for natural rubber as the minimum stress level was gradually increased. This sensitivity to R-ratio was not observed during tests performed on SBR. Also, they mentioned that, to the addition of a small minimum stress level can yield very beneficial effects to the fatigue crack growth behavior for certain rubber compounds, while producing no changes for other compounds. Corum et al.[16]have carried out tension-tension, reversed (tension-compression), and compression-compression) fatigue tests. They used the results of the fatigue tests to put recommendations about the fatigue criteria.

Mars and Fatemi [17] have demonstrated that, the crack energy approach provides a more successful framework for addressing commonly encountered failures of complex loading history.

Garnier et al. [18]have investigated the effect of cyclic loading on the viscoelastic properties of filled rubbers. They found that, the viscoelastic properties of the filled rubbers have been improved during cyclic loading tests. This phenomenon is not observed in unfilled rubber.

In the present work, the effect of type loading, stress amplitude, minimum stress and minimum strain on the fatigue lifetime of styrene butadiene (SBR) and nitrile butadiene (NBR) rubbers will be investigated with different carbon black contents.

\section{Experiments}

\subsection{Materials and specimens preparation}

In the present work, two types of rubber, namely, styrene butadiene (SBR-1502) and nitrile-butadiene rubber (NBR) are used in experiments. Styrene butadiene (SBR-1502) has styrene content of $23.5 \%$, with specific gravity of $0.945 \pm 0.005$ and Moony viscosity (ML4) of about 52 at $373 \mathrm{~K}$ while nitrile-butadiene rubber (NBR) has acrylonitrile content of $33 \%$, with specific gravity of $0.990 \pm 0.005$ and moony viscosity (ML4) of about 45 at $373 \mathrm{~K}$. Different concentrations of N550 carbon black contents of 0,20,30,50 and $70 \mathrm{phr}$ (parts per hundred of rubber by weight) are used while the concentrations of the remaining additives were not changed to compose a rubber formulations namely S0, S1, S2, S3, S4 and N0, N1, N2, N3, N4 respectively. These rubbers were adopted through out the current tests. The formulation of rubber compounds used in this study are given in Table 1. 
Abdullah Mohammed et al.

Table 1.

Composition of carbon black filled SBR and NBR systems.

\begin{tabular}{|c|c|c|c|c|r|r|r|r|r|r|}
\hline $\begin{array}{c}\text { Ingredients } \\
\text { Phr. }^{(\mathbf{a})}\end{array}$ & \multicolumn{10}{|c|}{ Formula No. } \\
\cline { 2 - 13 } & $\mathbf{S}$ & $\mathbf{S}$ & $\mathbf{S}$ & $\mathbf{S}$ & $\mathbf{S}$ & $\mathbf{N}$ & $\mathbf{N}$ & $\mathbf{N}$ & $\mathbf{N}$ & $\mathbf{N}$ \\
\hline SBR-1502 & 1 & 1 & 1 & 1 & 1 & - & - & - & - & - \\
\hline NBR & - & - & - & - & - & 1 & 1 & 1 & 1 & 1 \\
\hline ZnO & 5 & 5 & 5 & 5 & 5 & 5 & 5 & 5 & 5 & 5 \\
\hline Stearic acid & 2 & 2 & 2 & 2 & 2 & 2 & 2 & 2 & 2 & 2 \\
\hline Processing oil & 1 & 1 & 1 & 1 & 1 & 1 & 1 & 1 & 1 & 1 \\
\hline Carbon black & 0 & 2 & 3 & 5 & 7 & 0 & 2 & 3 & 5 & 7 \\
\hline MBTS & 2 & 2 & 2 & 2 & 2 & 2 & 2 & 2 & 2 & 2 \\
\hline DPG & 0 & 0 & 0 & 0 & 0 & 0 & 0 & 0 & 0 & 0 \\
\hline Sulfur & 2 & 2 & 2 & 2 & 2 & 2 & 2 & 2 & 2 & 2 \\
\hline
\end{tabular}

(a) Phr: Parts per hundred of rubber by weight.

All materials were provided from Marselleno Company for chemical industry and trade in Cairo, Egypt. Ingredients of the rubber compounds were mixed on a two-roll laboratory mill. The rubber compounds were vulcanized at $160 \pm 5^{\circ} \mathrm{C}$ to provide diabolo specimen. The rubber test specimens were prepared in stainless steel molds, Fig.3, inserted in a steel holder,Fig.4. The molds are made split lengthwise in order to facilitate the removal of the specimens after vulcanization. The vulcanization process often was carried out on a screw press equipped with an upper and lower heating plates as shown in Fig.5. Figure 6 (a) illustrates the main dimensions of diabolo test specimen, while Fig.6 (b) shows isometric view of the specimen. To adjust the heater temperature, the temperature of lower and upper plates were measured by a thermocouple at different thermostat temperature values. From this process it was found that the temperatures deviations were about \pm 5 degrees.

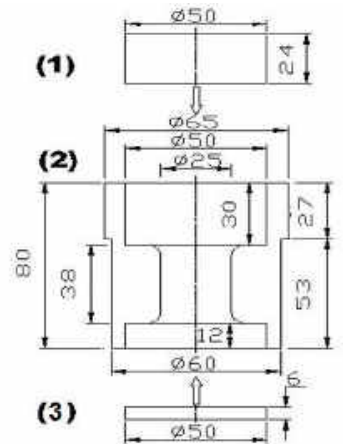

1-upper disc, 2- one half of the mold, 3-lower disc

(a)

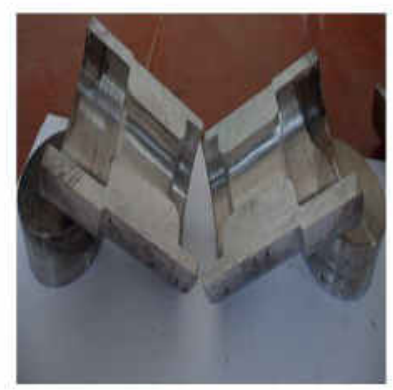

(b)

Fig. 3. Specimen mold: (a) Main dimensions, (b) Photograph of the mold. 


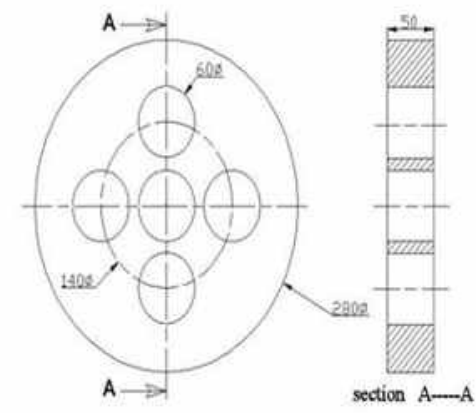

a

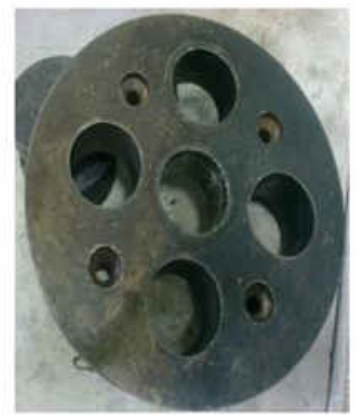

b

Fig. 4. Mold holder: a- Main dimensions, b- Photograph.

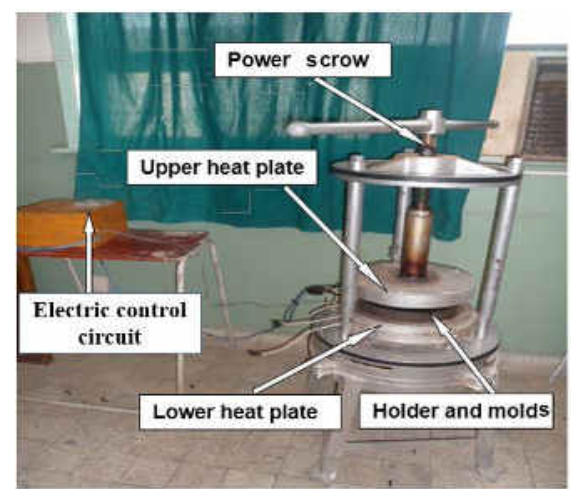

Fig. 5. A photograph of the screw press and heating system used in specimens preparation.

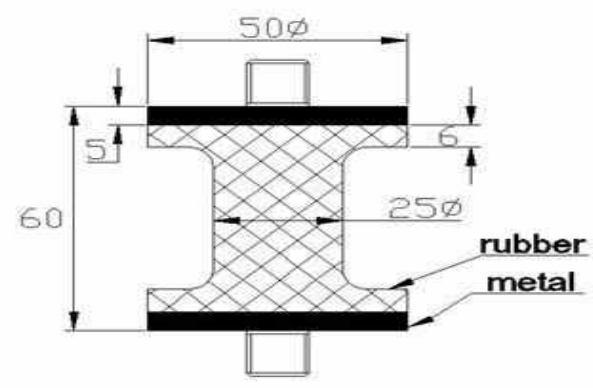

(a)

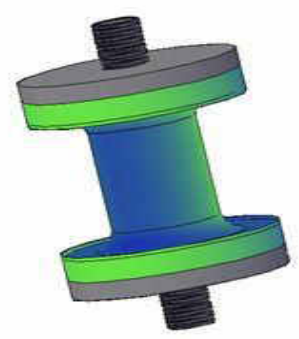

(b)

Fig. 6. Diabolo test specimen: (a) Main dimensions, (b) Isometric view.

\subsection{Fatigue test rig}

Fatigue tests were carried out on test rig shown in Fig.7. This rig was designed and manufactured for testing the fatigue behaviour of rubber. It proved to be reliable and have good repeatability. Full descriptions of this rig and how it works as well as its dynamics are given in Ref.[19]. The main idea of the fatigue test apparatus is to generate a sinusoidal 
excitation (sine wave), which provides cyclic stress (tension, compression, or combination of both of them) on the rubber diabolo specimen up to its failure. Figure 7 shows a section elevation and section side view of the fatigue test apparatus. Two sheet metals are glued to the diabolo specimen at its ends by using cyanoacrylate glue. Then the specimen is fastened to the test rig by means of two bolts. One of them is connected to the movable plate (15) while the other is connected to the load cell (10), which is connected to the fixed plate on the base (1). Load cell type 546QDT-A5 with $220 \mathrm{~kg}$ full capacity, tension and compression, and $20 \mathrm{~V}$ input is used to detect the load magnitude continuously. Figure 8 shows the calibration curve for the load cell. The load cell is connected to a $20 \mathrm{~V}$ power supply and the output volt is indicated, monitored and recorded using a data acquisition system. The data acquisition consists of PC, a data acquisition board (National Instrument NI USB-6210 16 inputs, 16-bit, 250ks/s multifunction I/O), the Lab- View software and a stopwatch to record the elapsed time. The driving motor (3-phase, $360 \mathrm{~V}, 3 \mathrm{hp}, 1440 \mathrm{rpm}$ ) was used to provide the desired speed, where the motor can be adjusted in the horizontal and vertical directions. A speed controller (IPM inverter model AS2-122 Adlee powertronic CO.LTD) is used to change the motor speed to a predetermined speed (frequency). To calibrate the speed controller, a digital speedometer tachometer (model DT6235B) was used to measure the motor speed. From Fig.9, it was found that the speed of the controller matches well the measured speed by the speedometer.
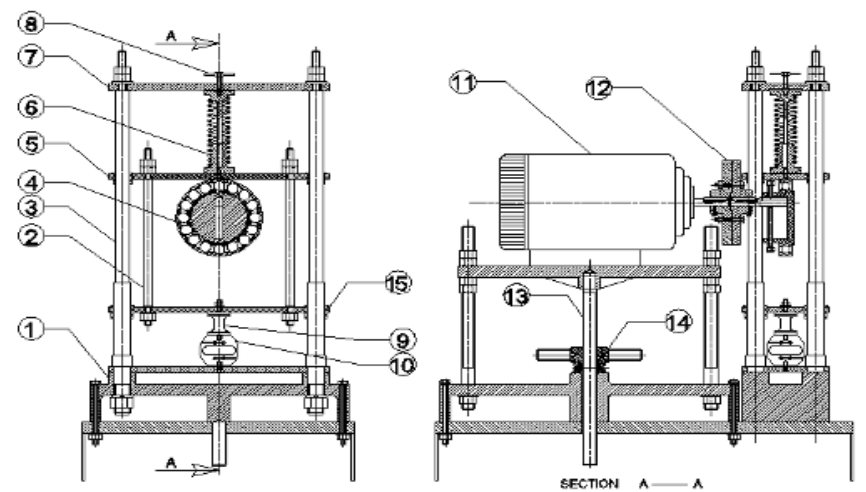

Fig. 7. Section elevation and section side view of rubber fatigue test apparatus (the specimen is in tension): 1-base, 2-column, 3-main column, 4-ball bearing, 5main plate, 6-cylindrical helical compression spring, 7-upper plate, 8-adjusting bolt, 9-rubber specimen, 10-load cell, 11-electric motor, 12-flange coupling, 13power screw, 14-bronze nut, 15- lower plate.

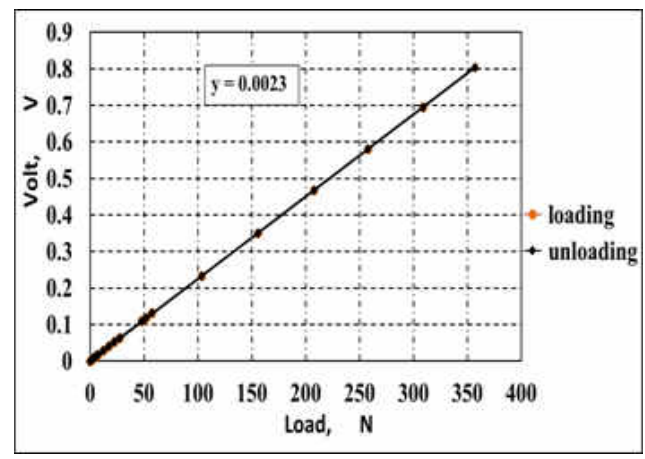

Fig. 8. Calibration curve of the load cell type of 546QDT-A5. 


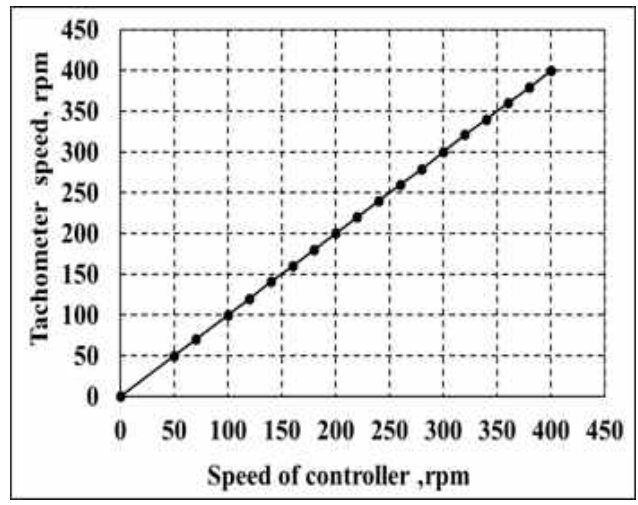

Fig. 9. Calibration curve of the speed controller.

\subsection{Experimental procedure}

In order to study the effect of loading conditions on the fatigue behaviour of rubber the adopted rubber materials were subjected to full relaxation tension $(\mathrm{R}=0)$, and nonrelaxation tension $\quad(0<\mathrm{R}<1)$ cyclic loading. Tests were carried out at frequency $3 \mathrm{~Hz}$ and at room temperature, $25 \pm 3^{\circ} \mathrm{C}$. Each test was carried out several times (not less than 3 ) and the number of cycles up to failure was recorded. The average of at least three repeated measurements was reported. The surface temperature of the specimen was measured by digital thermocouple just after failures. In full relaxation tension test, the specimens were subjected to constant minimum strain, which was equal to zero, and different maximum strains $(0.58,0.47$ and 0.42$)$. In the non-relaxation tension test, the specimens were subjected to constant maximum strain (0.47) and different minimum strains $\quad(0.13,0.18$ and 0.24). Figure 10 and Fig.11 show the uniaxial sine wave strain, to which the specimens were subjected through each test. The formulae, which were used to calculate the stress and strain parameters, are listed as follows:

The strain $\varepsilon$ :

$$
\varepsilon=\left(\mathrm{L}_{\mathrm{f}-\mathrm{L}}\right) / \mathrm{L}
$$

The stress amplitude $\sigma_{\mathrm{a}}$ :

$$
\sigma_{\mathrm{a}}=\left(\sigma_{\max }-\sigma_{\min }\right) / 2
$$

The mean stress $\sigma_{\mathrm{m}}$

$$
\sigma_{\mathrm{m}}=\left(\sigma_{\max }+\sigma_{\min }\right) / 2
$$

The $\mathrm{R}$ ratio with respect to the stress $\mathrm{R}_{\sigma:}$

$$
\mathrm{R}_{\sigma}=\sigma_{\min } / \sigma_{\max }
$$

The strain amplitude $\varepsilon_{\mathrm{a}}$ :

$$
\varepsilon_{\mathrm{a}}=\left(\varepsilon_{\max }-\varepsilon_{\min }\right) / 2
$$

The mean strain $\varepsilon_{\mathrm{m}}$ :

$$
\varepsilon_{\mathrm{m}}=\left(\varepsilon_{\max }+\varepsilon_{\min }\right) / 2
$$

The $\mathrm{R}$ ratio with respect to the strain $\mathrm{R}_{\varepsilon:}$

$$
\mathrm{R}_{\varepsilon}=\varepsilon_{\min } / \varepsilon_{\max }
$$

The uniaxial strain with respect to time $\varepsilon(\mathrm{t})$ :

$$
\varepsilon(\mathrm{t})=\varepsilon_{\mathrm{m}}+\varepsilon_{\mathrm{a}} \cdot \sin (2 . \pi . \mathrm{f.t})
$$


Where, $L_{f}$ and $L$ are the final and original lengths of specimen, $\sigma_{\max }$ and $\sigma_{\min }$ are the maximum and the minimum stresses, $\varepsilon_{\max }$ and $\varepsilon_{\min }$ are the maximum and the minimum strains, $\mathrm{f}$ is the frequency in $\mathrm{Hz}$ and $\mathrm{t}$ is the time in sec.

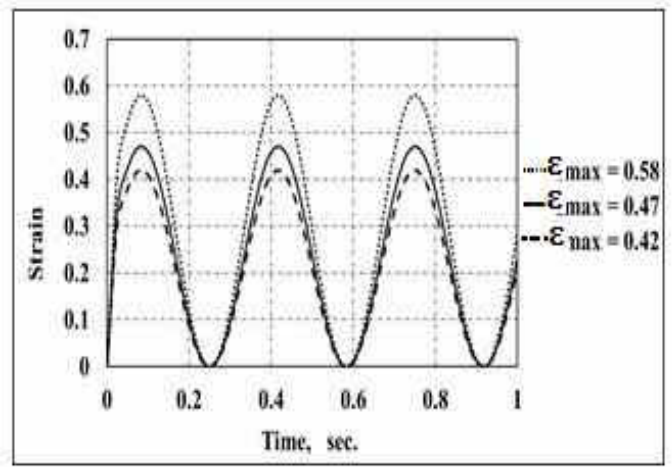

Fig. 10. Sine wave profile of uniaxial strain in Full relaxation tension test, at $f=3$ $\mathrm{Hz}$ and $\varepsilon_{\min .}=0$.

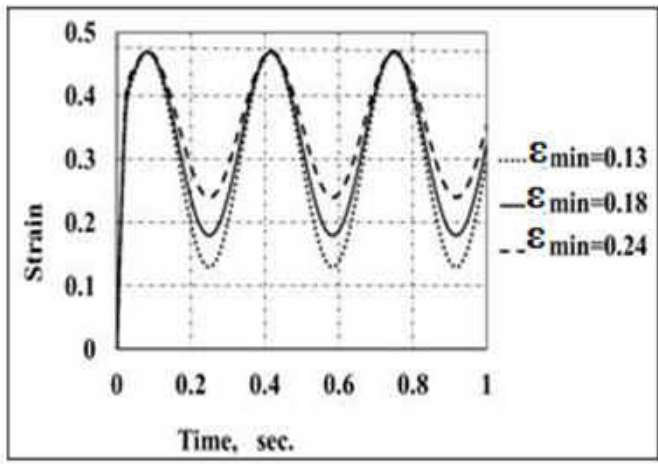

Fig. 11. Sine wave profile of uniaxial strain in Non-relaxation tension test at constant $\varepsilon_{\max }=0.47$ and $\mathrm{f}=3 \mathrm{~Hz}$.

\section{Results and discussion}

\subsection{Full relaxation tension test}

In this test, specimens were subjected to uniaxial strain at full relaxation tension and the stress was measured by the load cell. Figures 12 and 13 show the stress sine wave, to which SBR and NBR specimens were subjected, respectively. The fatigue lifetime of the adopted rubber materials is mainly dependent on the maximum strain (or maximum stress). It was found that the crack was initiated at the middle of the specimen or around its middle. Then, the crack propagated and eventually led to failure. At failure, the specimen was broken into two pieces. This is in agreement with the results published in literatures [12]. Figures 14 and 15 show the fatigue properties (relation between stress amplitude and number of cycles that brought about failure, S-N curve) for SBR and NBR respectively, with different carbon contents $(0,20,30,50$ and $70 \mathrm{Phr}$ of $\mathrm{CB})$. From these figures, it is clear that, the number of cycles increase with the decrease of the stress amplitude. This may be attributed to the fact that the increase in the load increases the energy dissipation as heat. This, in turn, will bring about increase in the temperature of the specimen. The elevated temperature will cause degradation of the mechanical properties of the specimen material. This will eventually lead to rapid failure of the specimen. From Figs .14 and 15 it 
can also be noticed that the number of cycles up to failure (lifetime) increases with the increase of the carbon black (CB) content. In other words, the increase of CB addition increases fatigue resistance of the rubber, at the test conditions used in the experiments. Comparing Figs.14 and 15, it is clear that the number of cycles up to failure of NBR compound is greater than that of SBR. Also, the fatigue properties (relation between maximum strain with number of cycles that induced failure, $\varepsilon-\mathrm{N}$ curve) for SBR and NBR respectively, are shown in Figs.16 and 17. From these figures, it is clear that, the fatigue lifetime decreases with the increase of the maximum strain in both materials SBR and NBR. Figures 18 and 19 show the variation of maximum stress with number of cycles at constant maximum strains $(0.58,0.47$ and 0.42$)$, to which SBR and NBR with $50 \mathrm{Phr}$ of CB specimens were subjected. It is clear that, the maximum stress decreases rapidly after few cycles and then continues to decrease with increase of cycles but at lower rate up to failure. This may be attributed to softening of rubber when it was subjected to cyclic loading. This phenomenon is conventionally referred to in literatures as Mullins effect [20,21].

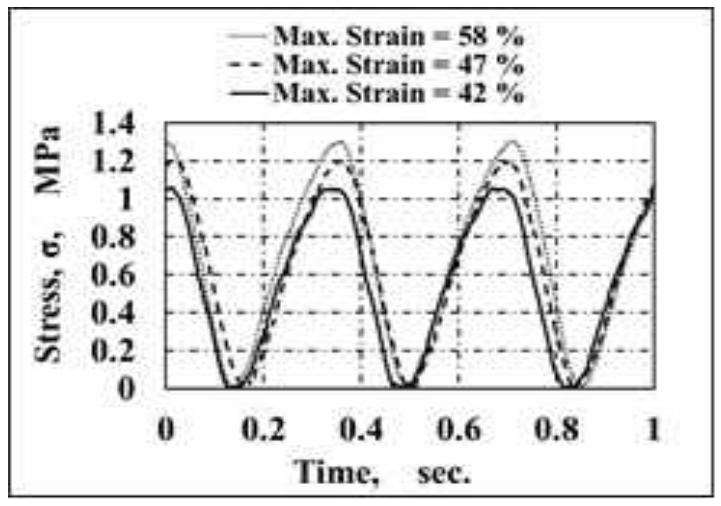

Fig. 12. Sine wave of stress at max. strain is constant, $f=3 \mathrm{~Hz}$ in full relaxation tension test on SBR with $50 \mathrm{Phr}$ of $\mathrm{CB}$.

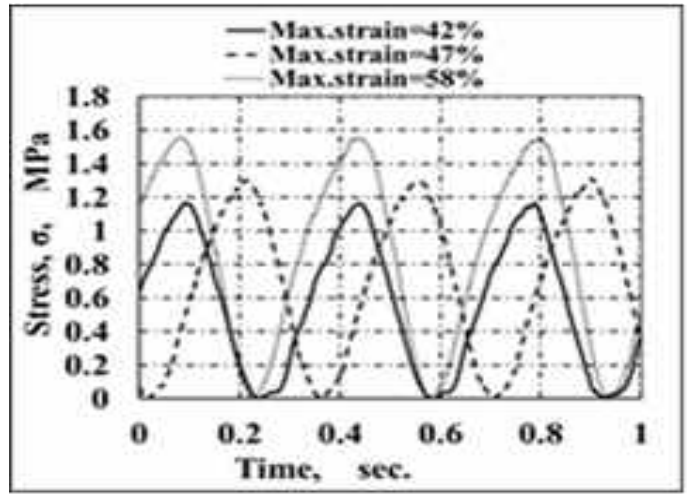

Fig. 13. Sine wave of stress at max. strain is constant, $f=3 \mathrm{~Hz}$ in full relaxation tension test on NBR with $50 \mathrm{Phr}$ of CB. 
Abdullah Mohammed et al.

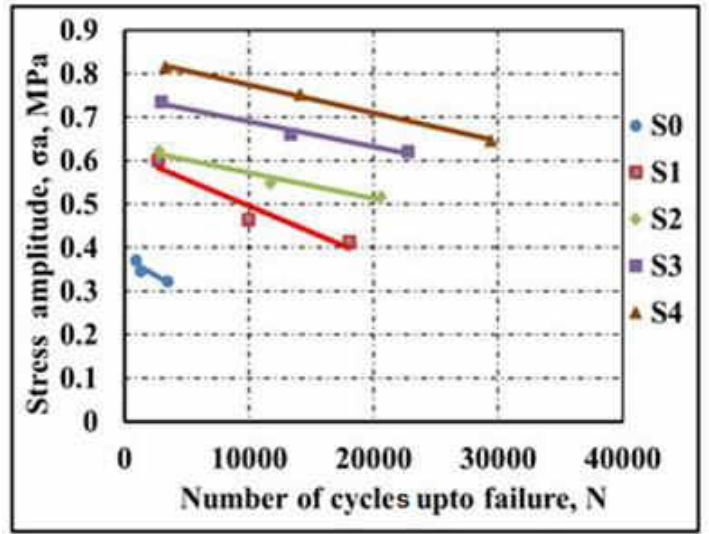

Fig. 14 . Fatigue properties of unfilled and filled of SBR compounds in full relaxation tension test (Stress amplitude influence).

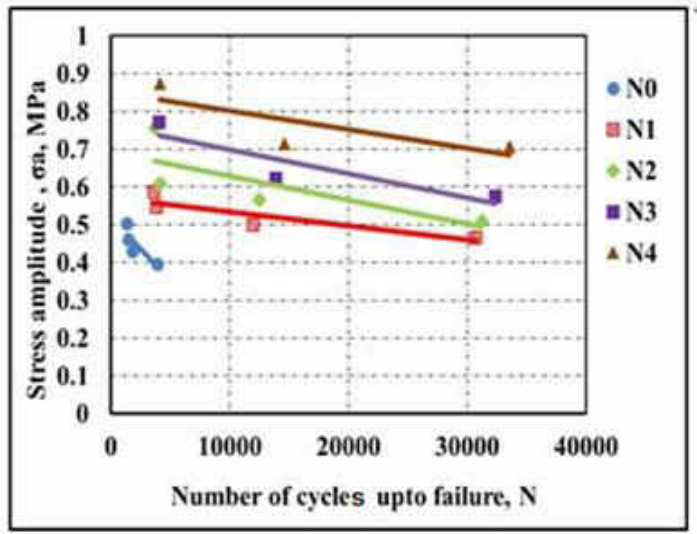

Fig. 15. Fatigue properties of unfilled and filled of NBR compounds in full relaxation tension test (Stress amplitude influence).

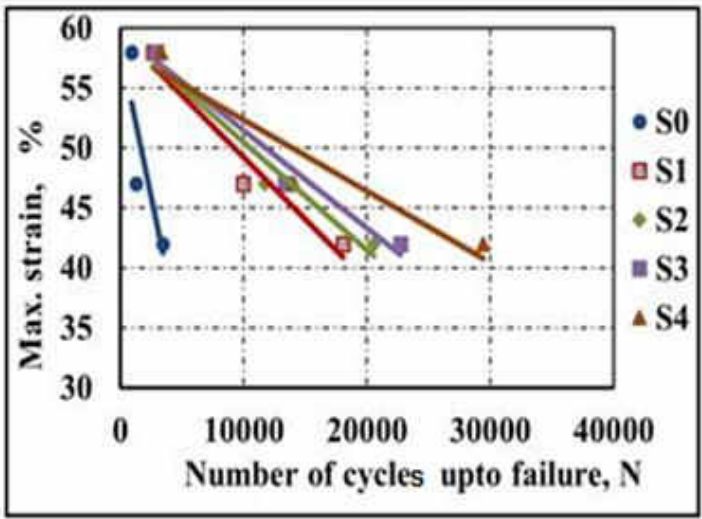

Fig. 16. Fatigue properties of unfilled and filled of SBR compounds in full relaxation tension test (Max. strain influence). 


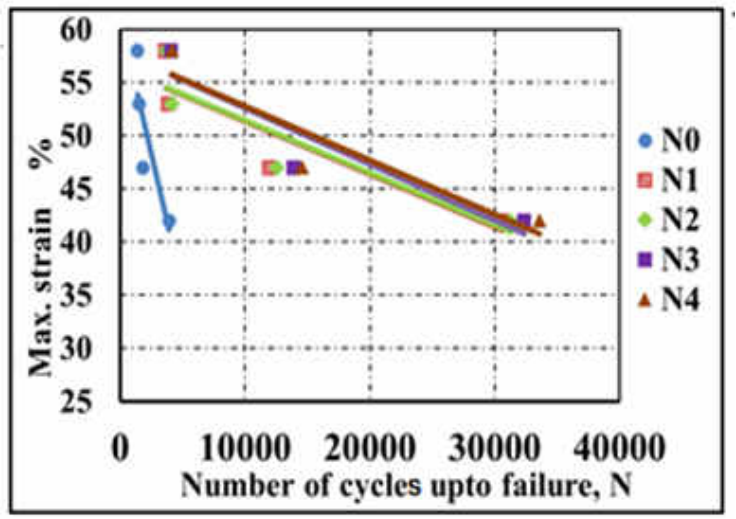

Fig. 17. Fatigue properties of unfilled and filled of NBR compounds in full relaxation tension test (Max. strain influence).

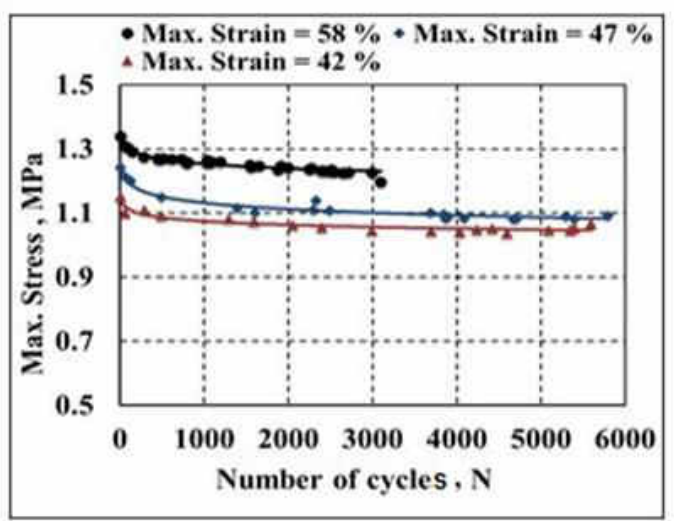

Fig. 18. Variations of max. stress with number of cycles at constant max. strain in full relaxation tension test on SBR with $50 \mathrm{Phr}$ of $\mathrm{CB}, \mathrm{R}=0$.

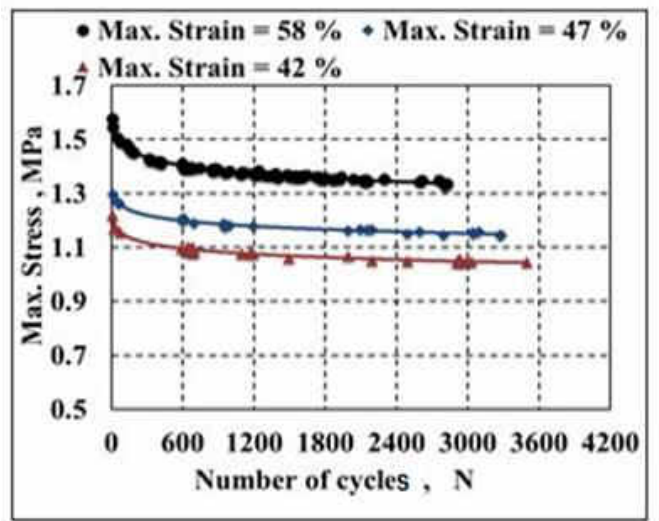

Fig. 19. Variations of max. stress with number of cycles at constant max. strain in full relaxation tension test on NBR with $50 \mathrm{Phr}$ of $\mathrm{CB}, \mathrm{R}=0$. 


\subsection{Non-relaxation tension test}

The specimens were subjected to uniaxial strain in non-relaxation test at a constant maximum strain (0.47) and three values of the minimum strains, namely, 0.13, 0.18 and 0.24 . The stress was measured by the load cell. Figures 20 and 21 show the sine wave of maximum stress, to which SBR and NBR specimen were subjected. From these figures, the minimum and maximum stresses increase with the increase of the minimum strain. This test was carried out to study the effect of minimum strain, minimum stress and $R_{\varepsilon}$ ratio on fatigue lifetime. Figures 22 and 23 show fatigue properties of unfilled and filled of SBR and NBR compounds in non-relaxation tension test with constant maximum strain. These figures illustrate the variation of stress amplitude with the number of cycles that caused failure. It is clear that, the number of cycles decreases with the increase of the stress amplitude. Figures 24 and 25 illustrate the fatigue properties of unfilled and filled SBR and NBR compounds in non-relaxation tension test. These figures show the variation of maximum stress with the number of cycles that induced failure. From these figures it is clear that the number of cycles up to failure increases with the increase of the maximum stress. It is well known that the number of cycles inducing failure decreases with the increase of the applied stress. Therefore, the results observed in Figs. 24 and 25 seem to be contradicting with the predicting ones. However, this may be explained as follows. The increase in the maximum stress is due to the increase in the minimum strain. The effect of the minimum strain on the fatigue lifetime is shown in Figs. 26 and 27. From these figures it is can be noticed that the number of cycles increases with the increase of $R_{\varepsilon}$ ratio, i.e. increase in minimum strain and, in turn, the increase of the maximum stress. Consequently, it can be concluded that the increase of the minimum strain is beneficial to fatigue lifetime. From the figures, it can also be noticed that the number of cycles up to failure (lifetime) increases with the increase of the carbon black (CB) content. Figures 28 and 29 show the variation of maximum stress with number of cycles at constant minimum strain $(0.13,0.18$ and 0.14$)$, to which SBR and NBR with $50 \mathrm{Phr}$ of CB specimens were subjected. It is clear that, the maximum stress decreases rapidly after a few cycles and then continuous to decrease with increase of the number of cycles but at lower rate up to failure. This may be attributed to softening of rubber when it was subjected to cyclic loading. This phenomenon is conventionally referred to in literatures as Mullins effect $[20,21]$.

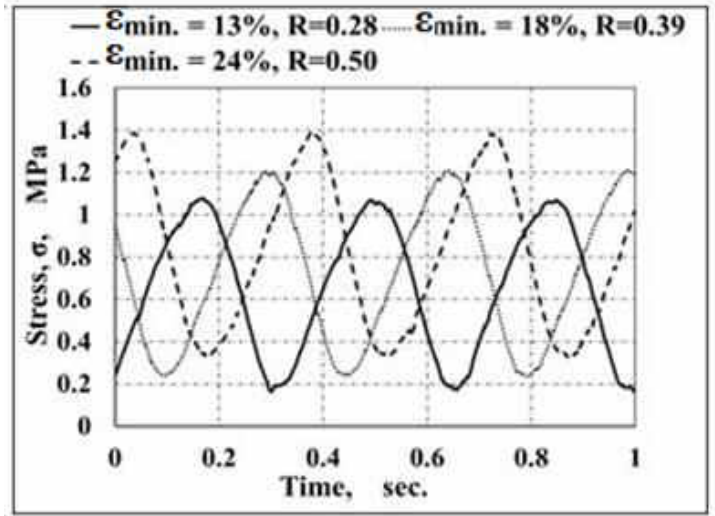

Fig. 20. Sine wave of stress at max. strain is constant, $f=3 \mathrm{~Hz}$ in non-relaxation tension test on SBR with $50 \mathrm{Phr}$ of CB. 


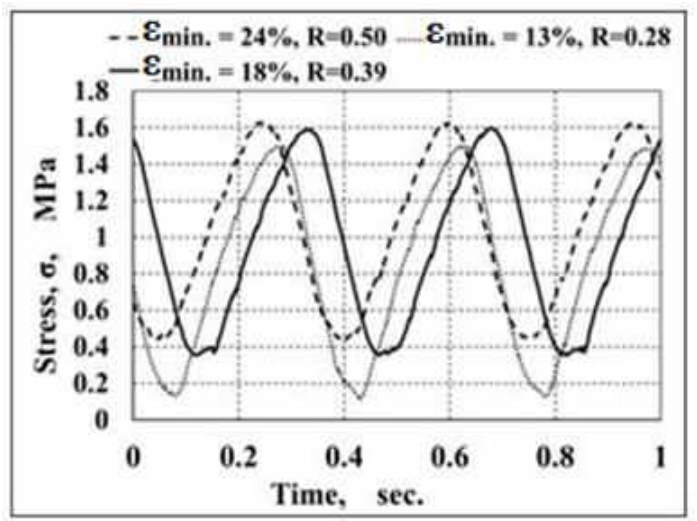

Fig. 21. Sine wave of stress at max. strain is constant, $f=3 \mathrm{~Hz}$ in non-relaxation tension test on NBR with $50 \mathrm{Phr}$ of CB.

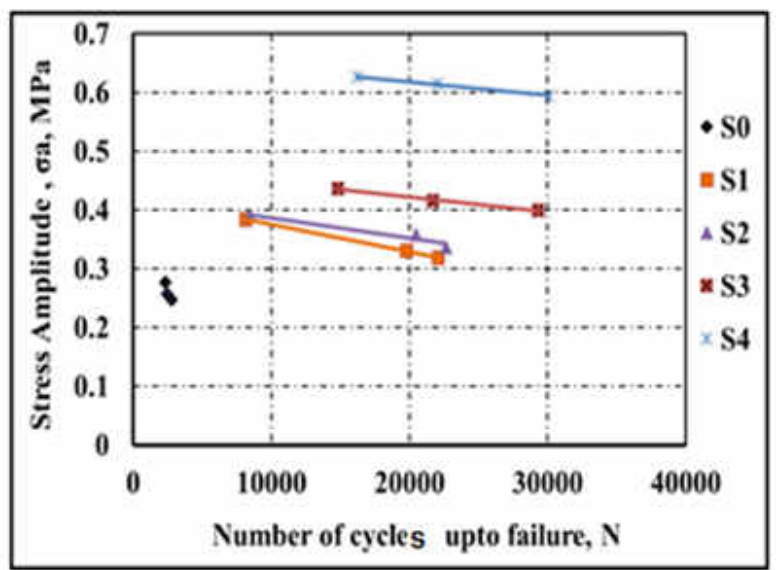

Fig. 22. Fatigue properties of unfilled and filled of SBR compounds in nonrelaxation tension test (Stress amplitude influence).

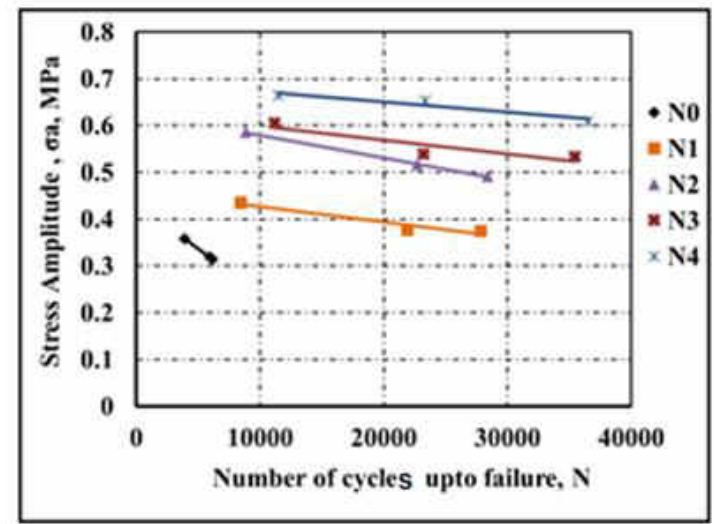

Fig. 23. Fatigue properties of unfilled and filled of NBR compounds in nonrelaxation tension test (Stress amplitude influence). 
Abdullah Mohammed et al.

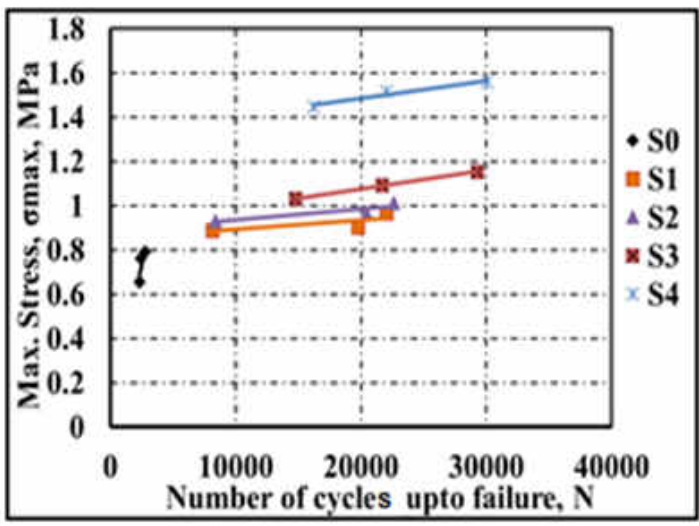

Fig. 24. Fatigue properties of unfilled and filled of SBR compounds in nonrelaxation tension test (max. stress influence).

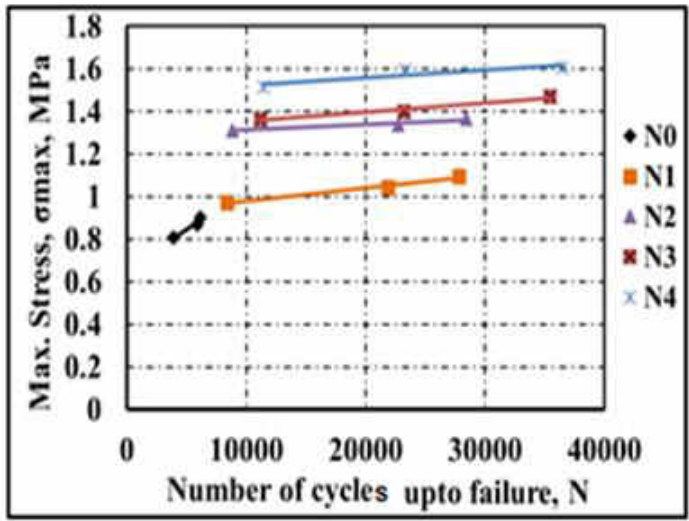

Fig. 25. Fatigue properties of unfilled and filled of NBR compounds in nonrelaxation tension test (max. stress influence).

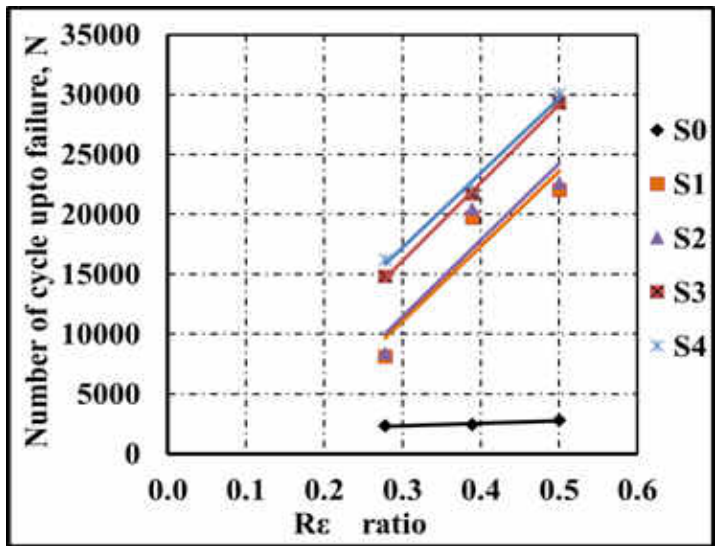

Fig. 26. Fatigue properties of unfilled and filled of SBR compounds in nonrelaxation tension test ( $R \varepsilon$ ratio influence). 


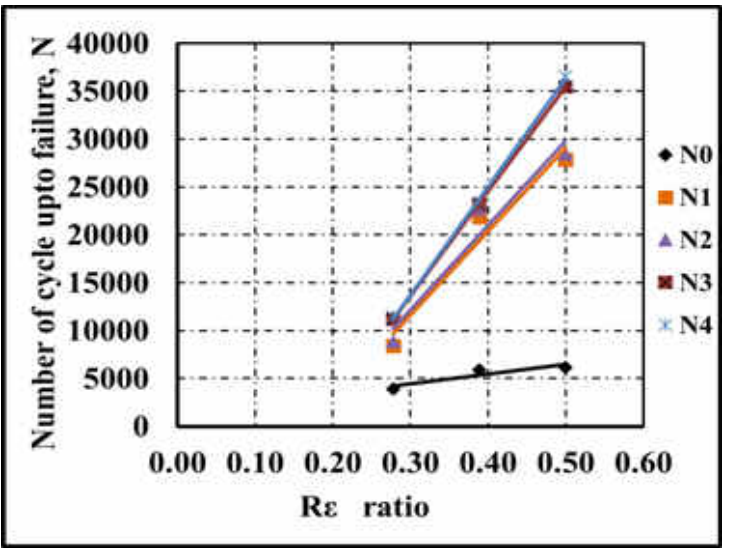

Fig. 27. Fatigue properties of unfilled and filled of NBR compounds in nonrelaxation tension test ( $\mathrm{R} \varepsilon$ ratio influence).

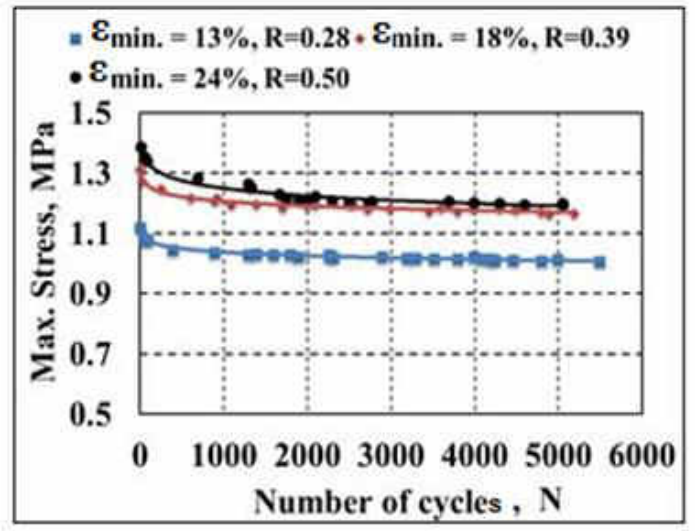

Fig. 28. Variations of max. stress with number of cycles at constant min. strain in non-relaxation tension test on SBR with $50 \mathrm{Phr}$ of CB.

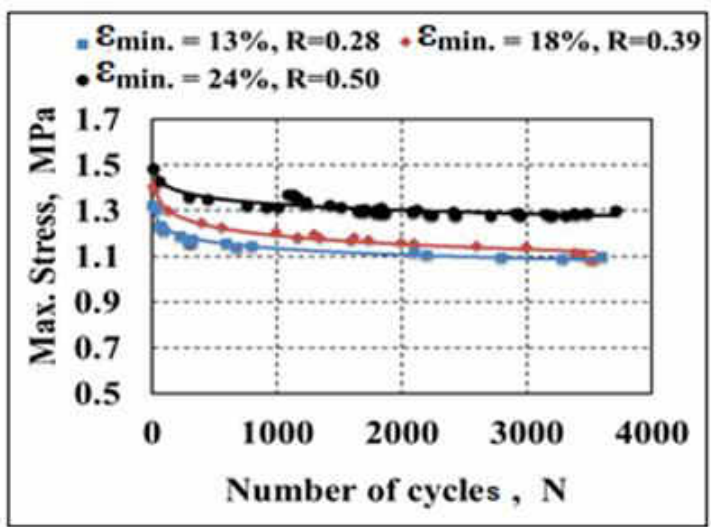

Fig. 29. Variations of max. stress with number of cycles at constant min. strain in non-relaxation tension test on NBR with $50 \mathrm{Phr}$ of CB. 


\subsection{Effect of loading condition on surface temperature at failure}

When a rubber component filled with carbon black is subjected to loading, the rubber matrix around carbon black is strained more than the rest and carbon black is separated from the matrix. This mechanism causes dissipation of the energy as heat in the specimen. Figures 30-33 illustrate comparison between the surface temperature just after failure of SBR and NBR compounds in full relaxation and non-relaxation tension tests. In these figures, it is clear that the surface temperature increases with increase of the carbon black contents in all tested specimens. From Figs. 30 and 31, it is obvious that in full relaxation tension test with the same CB contents in SBR and NBR compounds the surface temperature just after failure increases with the increase of maximum strain. From Figs.32 and 33, it can be noticed that in non-relaxation tension test with the same CB content in SBR and NBR compounds the surface temperature just after failure decreases with the increase of minimum strain.

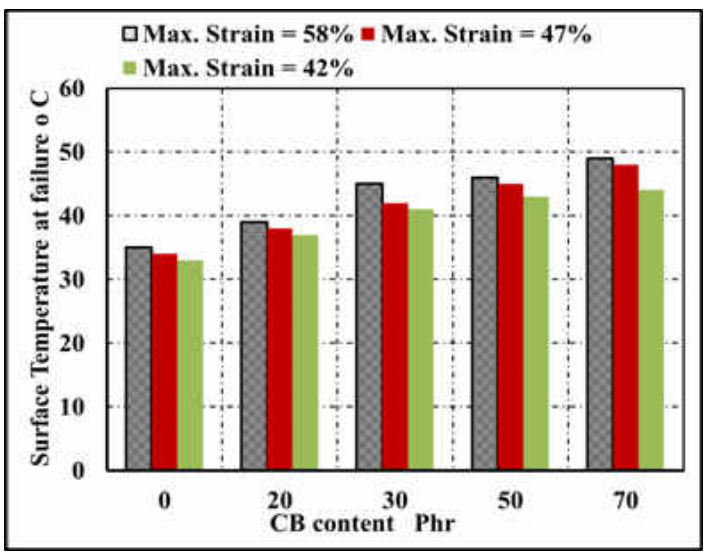

Fig. 30. Surface temperature just after failure for the SBR compounds with different $\mathrm{CB}$ contents in full relaxation tension test.

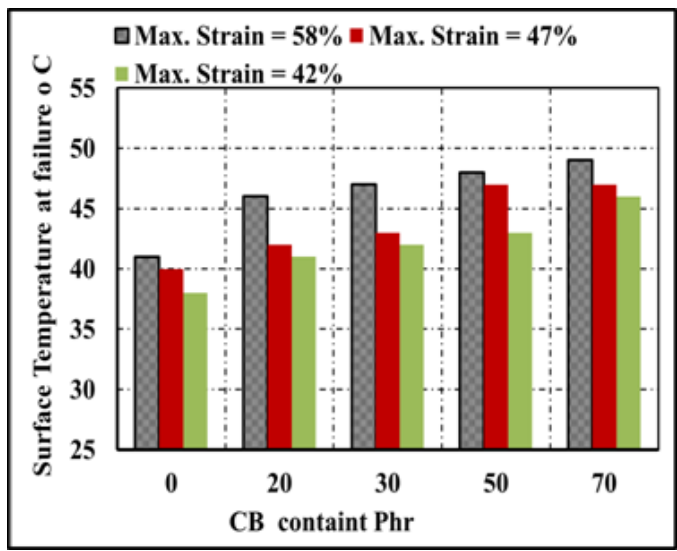

Fig. 31. Surface temperature just after failure for the NBR compounds with different $\mathrm{CB}$ contents in full relaxation tension test. 


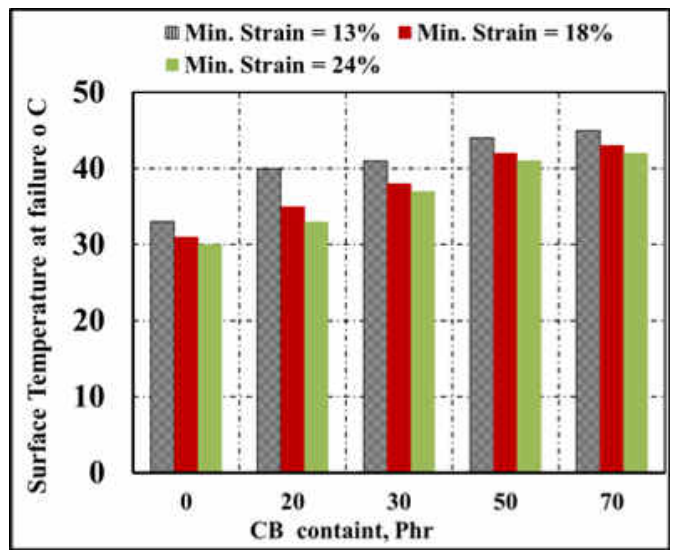

Fig. 32. Surface temperature just after failure for the SBR compounds with different $\mathrm{CB}$ contents in non-relaxation tension test.

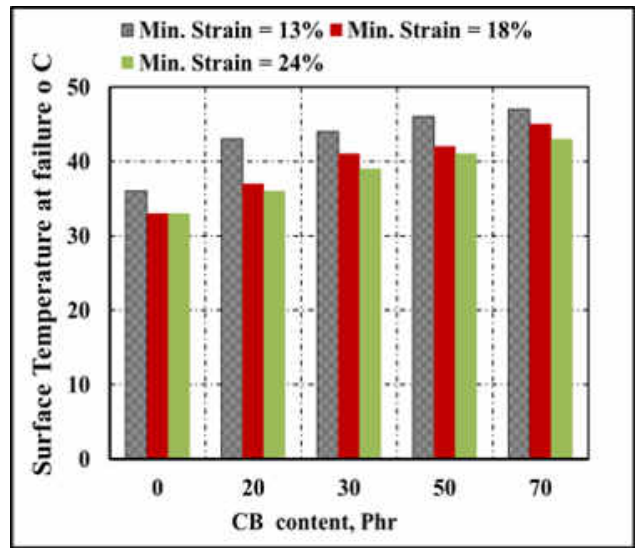

Fig. 33. Surface temperature just after failure for the NBR compounds with different $\mathrm{CB}$ contents in non-relaxation tension test.

\section{Conclusions}

From the current investigation of the influence of the cyclic loading on fatigue behaviour of SBR and NBR compounds, the following points can be concluded:-

1- In full relaxation tension test $(\mathrm{R}=0)$, fatigue lifetime increases with the decrease of the maximum strain. The decrease of the maximum strain is followed by decrease in the maximum stress and stress amplitude.

2- In non-relaxation tension test $(R>0)$, fatigue lifetime increases with the decrease of the stress amplitude.

3- In non-relaxation tension test $(\mathrm{R}>0)$, fatigue lifetime increases with increase of the minimum strain, in spite of the increase of the maximum stress. Consequently, it can be concluded that, the increase of the minimum strain is beneficial to fatigue resistant.

4- Fatigue lifetime of rubber can be improved by increasing the carbon black additions.

5- The surface temperature just after failure of SBR and NBR compounds at all test conditions used in this work increases with the increase of carbon black contents. 
6- The surface temperature just after failure of SBR and NBR compounds at full relaxation test increases with the increase of the maximum strain, and this temperature decreases with the increase of the minimum strain at non-relaxation tension test.

\section{References}

[1] Mars W. V, 2004, "Factors that Affect the Fatigue Life of Rubber: A Literature Survey" J. Rubber Chem. Technol., 77, pp. 391-412.

[2] Chung D. D. L., 2001, "Review Materials for Vibration Damping” Mater. Sci., 36, pp. 5733 5737.

[3] Mars W. V, and Fatemi A., 2002, "A literature Survey on Fatigue Analysis Approaches for Rubber” Int. J. Fatigue, 24, pp. 949-961.

[4] Harbour R. J., 2006, "Multiaxial Deformation and Fatigue of Rubber under Variable Amplitude Loading" $\mathrm{Ph}$. D, thesis, the University of Toledo.

[5] Eiiui M. D., 2001, "Mechanical Fatigue," Engineering with Rubber How to Design Rubber Components, Alan N. Gent, ed., Hanser, pp. 139-175.

[6] Mars W. V, and Fatemi A., 2003, "Fatigue Crack Nucleation and Growth in Filled Natural Rubber" Ltd. Fatigue Fract Engng Mater Struct, 26(January), pp. 779-789.

[7] Post N. L., Case S. W., and Lesko J. J., 2008, "Modeling the Variable Amplitude Fatigue of Composite Materials : A review and evaluation of the state of the art for spectrum loading" Int. J. Fatigue, 30, pp. 2064-2086.

[8] Legorju-jago K., and Bathias C., 2002, "Fatigue Initiation and Propagation in Natural and Synthetic Rubbers" Int. J. Fatigue, 24, pp. 85-92.

[9] Gent A. N., 2005, "Strength of Elastomers," Science and Technology of Rubber, F.R.E. Mark, James E.Burak Erman, ed., Elsevier Academic Press, The University of Akron, Akron, Ohio, pp. 544-495.

[10] Kim J., and Jeong H., 2005, "A study on the Material Properties and Fatigue Life of Natural Rubber with Different Carbon Blacks” Int. J. Fatigue, 27, pp. 263-272.

[11] Abraham F., Alshuth T., and Jerrams S., 2005, "The Effect of Minimum Stress and Stress Amplitude on the Fatigue Life of Non Strain Crystallising Elastomers" Mater. Des., 26(3), pp. 239-245.

[12] Cam J.-B. LE, B.Huneau, and E.Verron, 2008, "Description of Fatigue Damage in Carbon Black Filled Natural Rubber” Fatigue Fract. Eng. Mater. Struct., 31, pp. 1031-1038.

[13] Saintier N., Cailletaud G., and Piques R., 2006, "Multiaxial Fatigue Life Prediction for a Natural Rubber" Int. J. Fatigue, 28, pp. 530-539.

[14] Harbour R. J., Fatemi A., and Mars W. V, 2008, "Fatigue life Analysis and Predictions for NR and SBR under Variable Amplitude and Multiaxial Loading Conditions" Int. J. Fatigue, 30, pp. 1231-1247.

[15] Harbour R., Fatemi A., and Mars W. V, 2006, "Fatigue Crack Growth of Rubber under Variable Amplitude Loading," international fatigue congress, Atlanta, Georgia.

[16] Corum J. M., Battiste R. L., and Ruggles M. B., 1998, "Fatigue Behavior and Recommended Design Rules for an Automotive Composite" Oak Ridge Natl. Lab., TN (United States).

[17] Mars W. V., and Fatemi A., 2004, "Analysis of Fatigue Life under Complex Loading: Revisiting Cadwell, Merill, Sloman, and Yost" Analysis, (9), pp. 1-17.

[18] Garnier P., Le Cam J.-B., and Grédiac M., 2013, "The Influence of Cyclic Loading Conditions on the Viscoelastic Properties of Filled Rubber" Mech. Mater., 56, pp. 84-94.

[19] Mohammed A., Emara K. M., and Nemat-alla M. M., 2013, "Design of Rubber Fatigue Behaviour Test Rig” J. Eng. Sci. Assiut Univ., 41(2), pp. 501-516.

[20] Brieu M., Diani J., Mignot C., and Moriceau C., 2010, "Stress Softening of Carbon Black Filled SBRs Submitted to Various Large Strain Uniaxial Tension Cycles” Procedia Eng., 2(1), pp. 1291-1296.

[21] Diani J., Fayolle B., and Gilormini P., 2009, "A Review on the Mullins Effect" Eur. Polym. J., 45(3), pp. 601-612. 


\section{تأثير الأحمال المتكررة على سلوك الكلال لمركبات الإسترين بيوتادين والنيتريل بيوتادين المطاطية مع إختلاف محتوى الكربون الأسود}

يعتبر سلوك الكلال في المطاط من الصفات و السمات الهامة نظر اً للإستخدامات الواسعة له في التطبيقات

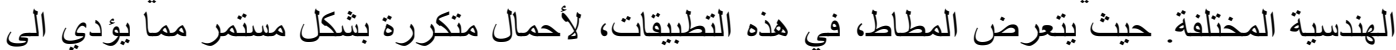

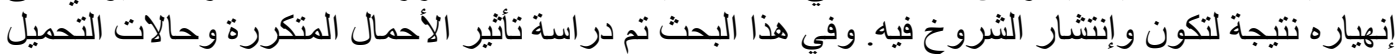

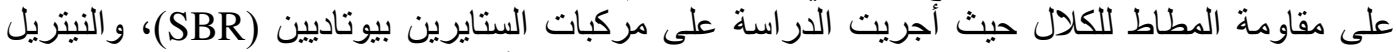

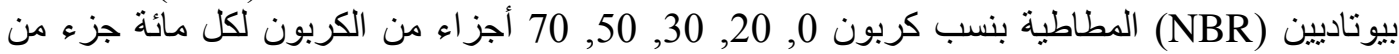

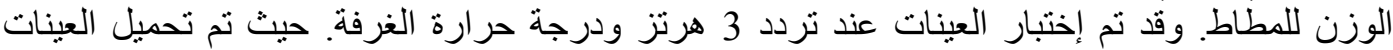

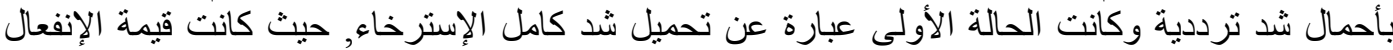

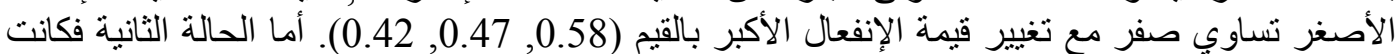
عبارة عن تحميل شد بدون إسترخاء حيث تم تثبيت القيمة العظمى للإنفعال عند (0.47) مع الإنة

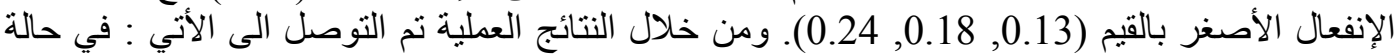

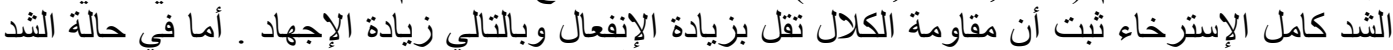

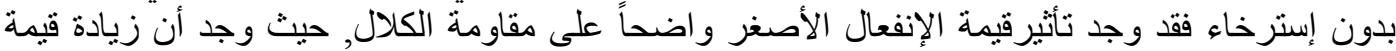

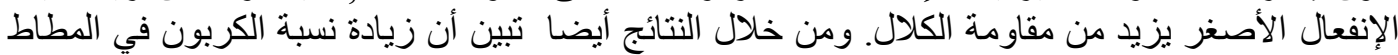

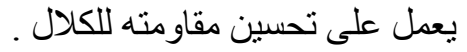

